\title{
Content Based Image Retrieval Using Gray Level Co-Occurrence Matrix to Detect Pneumonia in X-Ray Thorax Image
}

Content Based Image Retrieval Menggunakan Metode Gray Level Co-Occurrence Matrix Untuk Mendeteksi Penyakit Pneumonia Pada Citra X-Ray Thorax

\author{
Wilis Kaswidjanti1*, Bambang Yuwono², Nisa'ul Azizah³ ${ }^{3}$ Nur Heri Cahyana ${ }^{4}$ \\ 1,2,3,4 Informatika, Universitas Pembangunan Nasional Veteran Yogyakarta, Indonesia \\ 1*wilisk@upnyk.ac.id, ${ }^{2}$ bambangy@upnyk.ac.id, ${ }^{3}$ nisa.azizah@gmail.com, \\ ${ }^{4}$ dsnurheri@gmail.com \\ *: Penulis korenspondensi (corresponding author)
}

\section{Informasi Artikel}

Received: May 2021

Revised: June 2021

Accepted: June 2021

Published: August 2021

\section{Abstract}

\section{Purpose:}

This study aims to detect the presence of pneumonia or not in thorax x-ray images using the Gray Level Co-Occurence Matrix (GLCM) method as well as find out the accuracy of the accuracy of pneumonia detection accuracy.

Design/methodology/approach:

The process of detecting pneumonia in thorax $x$-ray images can use Content Based Image Retriveal (CBIR). CBIR is an image search method by comparing the input image feature with the image feature in the database. Extraction features $x$-ray texture of thorax in pneumonia detection using Color Histogram, Discrete Cosine Transform and Gray Level Cooccurence Matrix (GLCM). From the day of extraction the feature will be carried out similarity measurements with database images using Euclidean Distance..

\section{Findings/result:}

The test results showed that the GLCM extraction feature with euclidean distance similarity measurements gained $95 \%$ accuracy on 100 training data and 20 test data, with the number of images displayed 6. Whereas when testing using data that has been trained produces $100 \%$ accuracy.

Originality/value/state of the art:

The difference between this study and previous research is in the pre-processing method section of imagery. This preprocessing process, x-ray image of thorax is carried out color histogram and discrete cosine transform process. Then continued the extraction of features using GLCM. The output of this system is the result of detection whether normal or pneumonia. 
Keywords: Pneumonia, Image Processing, CBIR, GLCM, Euclidean Distance

Kata kunci: Pneumonia, Image Processing, CBIR, GLCM, Euclidean Distance
Abstrak

\section{Tujuan:}

Penelitian ini bertujuan untuk mendeteksi adanya Pneumonia atau tidak pada citra $\mathrm{x}$-ray thorax menggunakan metode Gray Level Co-Occurence Matrix (GLCM) serta mengetahui akurasi tingkat akurasi deteksi pneumonia.

\section{Perancangan/metode/pendekatan:}

Proses deteksi penyakit Pneumonia pada citra $\mathrm{x}$-ray thorax dapat menggunakan Content Based Image Retriveal (CBIR). CBIR adalah suatu metode pencarian citra dengan melakukan perbandingan antara fitur citra input dengan fitur citra yang ada didalam database. Ekstraksi fitur tekstur x-ray thorax dalam deteksi pneumonia menggunakan Color Histogram, Discrete Cosine Transform dan Gray Level Cooccurence Matrix (GLCM). Dari hari ekstraksi fitur tersebut akan dilakukan pengukuran kemiripan dengan citra database menggunakan jarak Euclidean Distance.

\section{Hasil:}

Hasil pengujian menunjukkan bahwa fitur ekstraksi GLCM dengan pengukuran kemiripan Euclidean Distance diperoleh akurasi sebesar 95\% pada data latih 100 dan data uji 20, dengan jumlah citra yang ditampilkan 6. Sedangkan bila pengujian menggunakan data yang sudah dilatihkan menghasilkan akurasi $100 \%$.

\section{State of the art:}

Perbedaan penelitian ini dengan penelitian sebelumnya adalah pada bagian metode pre processing citra. Proses pre processing ini, citra x-ray thorax di lakukan proses Color Histogram dan Discrete Cosine Transform. Kemudian dilanjutkan ekstraksi fitur menggunakan GLCM. Output dari sistem ini berupa hasil deteksi apakah normal atau pneumonia.

\section{Pendahuluan}

Deteksi pneumonia dapat dilakukan dengan membaca gambar citra x-ray thorax dengan benar pada bagian paru - paru dan biasanya dilakukan oleh dokter ahli. Citra x-ray thorax terdiri dari beberapa organ yaitu paru - paru, jantung dan tulang rusuk. Citra medis x-ray biasanya menyatu dalam inkonsistensi tinggi dan terdiri dari banyak bagian organ tubuh yang berbeda. Sehingga dibutuhkan fitur ekstraksi pada citra medis untuk memudahkan pembacaan citra $\mathrm{x}$ ray thorax.

Kualitas citra x-ray sering mengalami inkonsitensi disebabkan karena nodul (bintik bulatan atau oval) pada citra $\mathrm{x}$-ray thorax tidak dapat dideteksi karena tertutup oleh struktur anatomi 
(bagian X-ray thorax lain) ataupun karena rendahnya kualitas citra. Buruknya hasil visualisasi citra $\mathrm{x}$-ray disebabkan karena sedikit perbedaan redaman sinar-x antara jaringan kelenjar yang terkena penyakit paru-paru. Untuk memastikan bahwa nodul tertutup struktur anatomi tubuh atau tidak, biasanya, dilakukan pemeriksaan yang lebih mendalam menggunakan Computed Tomography (CT) scan. Citra hasil CT scan dapat menunjukkan letak nodul secara lebih jelas dan detail. Tetapi apabila penyebab sulitnya mendeteksi nodul karena rendahnya kualitas citra, maka citra $x$-ray tersebut dapat diperbaiki atau ditingkatkan kualitasnya sehingga nodul dapat terlihat lebih jelas oleh radiolog. Selain karena rendahnya kualitas citra, karakteristik nodul juga cenderung memiliki bentuk dan warna yang mirip dengan jaringan sel pada paru-paru [1].

Dalam pembacaan citra x-ray thorax, petugas medis sering memerlukan waktu yang lama karena tampilan masing - masing area tidak jelas. Tampilan area yang tidak jelas diakibatkan film yang kelebihan pencahayaan akan terlihat lebih gelap dari biasanya. Film dapat dipastikan kurang pencahayaan jika tidak dapat melihat tulang belakang pada bagian thoraks. Hasil citra X-ray thorax yang kurang baik maka akan disarankan untuk pengambilan kembali foto thorax, dimana untuk pengambilan kembali memerlukan biaya dan waktu yang lama. Berdasarkan hal tersebut dibutuhkan suatu aplikasi untuk membantu mempercepat petugas medis membaca hasil $\mathrm{x}$-ray yang kurang jelas.

Penelitian yang dilakukan oleh [2] dengan judul Content-based image retrieval for brain MRI : An Image-searching engine and population-based analysis to utilize past clinical data for future diagnosis. Penelitian menggunakan metode Atlet-based analysis yang ditujukan untuk mencari populasi hasil data dalam menentukan diagnosis selanjutnya. Penelitian yang dilakukan oleh [3] dengan judul Klasifikasi Penyakit Paru Berdasarkan Citra Rontgen dengan Metode Segmentasi Sobel. Hasil penelitian didapatkan dari perbandingan piksel antara hasil deteksi tepi terhadap region paru, yang mengklasifikasikan 6 (enam) jenis penyakit paru dengan interval persentase untuk penyakit bronkitis sebesar 1,43\% - 1,59\%, penyakit pleuritis $1,43 \%-1,59 \%$, penyakit pneumonia 2,00\% - 2,50\%, penyakit TBC 2,86\% - 3,79\%, penyakit emfisema 4,16\% - 4,76\% dan penyakit kanker paru 76,72\% - 94,85\%. Penelitian yang dilakukan oleh [4] Penelitian ini menghasilkan nilai pengujian $100 \%$ pada 41 sampel citra dimana nilai tersebut sesuai dengan sampel uji terhadap interval internsitas pixel. Dimana interval $0,49 \%-1,28 \%$ penyakit bronchitis, interval $1,43 \%-1,59 \%$ penyakit pleuritis, interval $2,00 \%-2,50 \%$ penyakit pneumonia, interval $2,86 \%-3,79 \%$ penyakit tbc, interval $4,17 \%$ $4,76 \%$ penyakit emfisema dan interval $76,72 \%$ - 94,85\% penyakit kanker paru. Penelitian yang dilakukan oleh [5] Penelitian ini menggunakan Learning vector quantization dengan akurasi data training terbaik sebesar $89,714 \%$ dan akurasi data test yang terbaik sebesar $74,00 \%$ yang didapat pada pengujian dengan learning rate $=0,4$. Penelitian yang dilakukan oleh [6] Penelitian ini menggunakan GLCM dan Neural Network untuk klasifikasi kualitas kematangan wortel berdasarkan tekstru kulit menghasilkan akurasi 72,50\%. Penelitian yang dilakukan oleh [7] Penelitian ini menggunakan GLCM dan KNN untuk identifikasi Jenis Anggrek menghasilkan akurasi rata-rata 77\%. Penelitian yang dilakukan oleh [8] Penelitian ini memanfaatkan GLCM citra buah jeruk keprok untuk klasifikasi mutu menghasilkan akurasi terbaik $82,5 \%$ dengan jumlah data latih sebanyak 20 , nilai distance $=2$ pada arah GLCM $45^{\circ}$. 


\section{Metode/Perancangan}

Diagram alir adalah bagan yang menunjukkan alir atau arus (flow) di dalam program atau prosedur sistem secara logika [9]. Pada penelitian ini terdapat beberapa flowchart yang digunakan untuk menggambarkan alur proses atau tahapan-tahapan yang digunakan. Perancangan proses identifikasi pneumonia digambarkan dalam flowchart pada Gambar 1.

Alur program yang ada di Gambar 1. merupakan alur keseluruhan yang akan digunakan untuk mencari hasil identifikasi penyakit pneumonia. Dimulai dengan input citra uji dan pemunculan citra database, setelah citra selesai dimunculkan, proses selanjutnya adalah ekstraksi fitur dengan metode color histogram. Lalu dilanjutkan dengan kompresi citra dengan metode Discrete Cosine Tranform yang biasa digunakan untuk kompresi citra JPEG. Lalu menggunakan metode GLCM untuk menghitung nilai pixel berdasarkan derajat keabuan suatu citra.

Lalu proses selanjutnya adalah perhitungan kesamaan (fiture matching) dengan citra yang ada pada database menggunakan nilai persamaan euclidean distances. Setelah itu akan muncul retrieved citra yang merupakan hasil dari persamaan citra uji dan citra database. Setelah keseluruhan proses selesai maka output yang akan keluar adalah teks yang menunjukkan apakah citra yang diproses terkena pneumonia atau tidak.

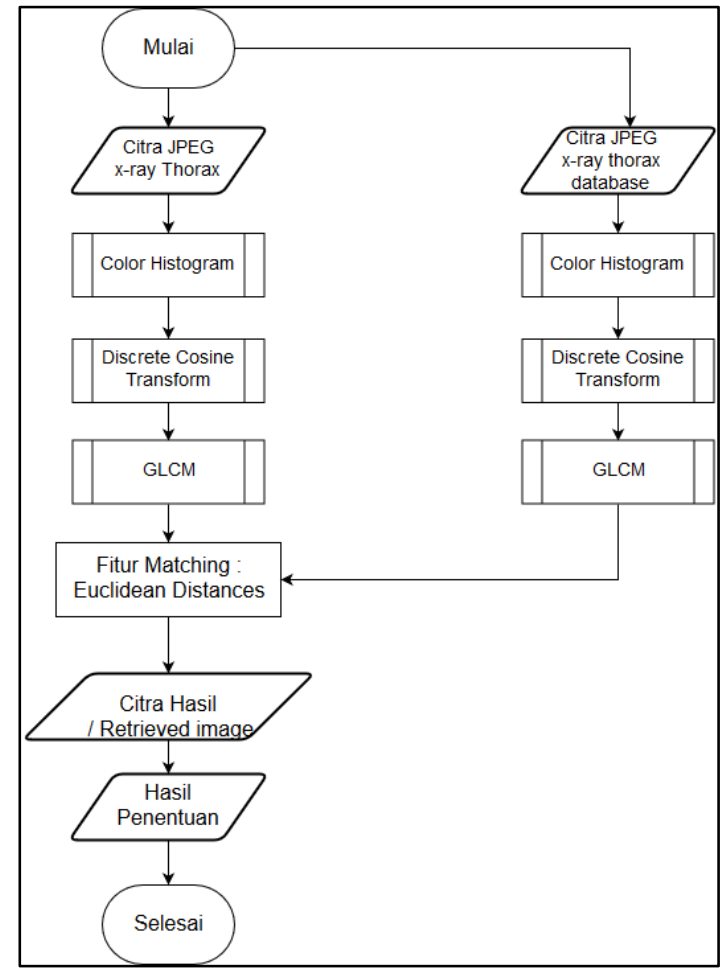

Gambar 1. Diagram Alir Deteksi Penyakit Pneumonia Pada Citra X-Ray Thorax

\subsection{Pengumpulan Data}

Jenis data citra $x$-ray thorax yang diambil yaitu data primer. Data primer tersebut diambil dari Rumah Sakit Khusus Paru (RSKP) Respira Bantul. Data citra $x$-ray thorax yang diambil berbentuk file jpeg. Adapun contoh gambar x-ray thorax bisa dilihat pada gambar 2 . 


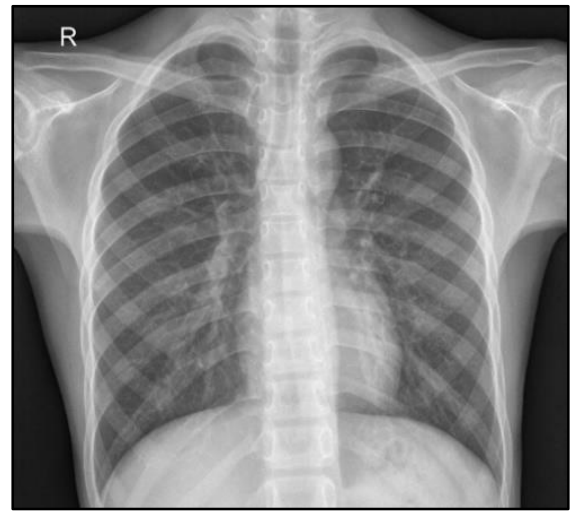

Gambar 2. Contoh data citra $x$-ray thorax

\subsection{Pengolahan Data}

Penelitian ini menggunakan tekstur sebagai parameter penentuan penyakit selain itu ditambah dengan penentuan derajat keabuan pada citra thorax.
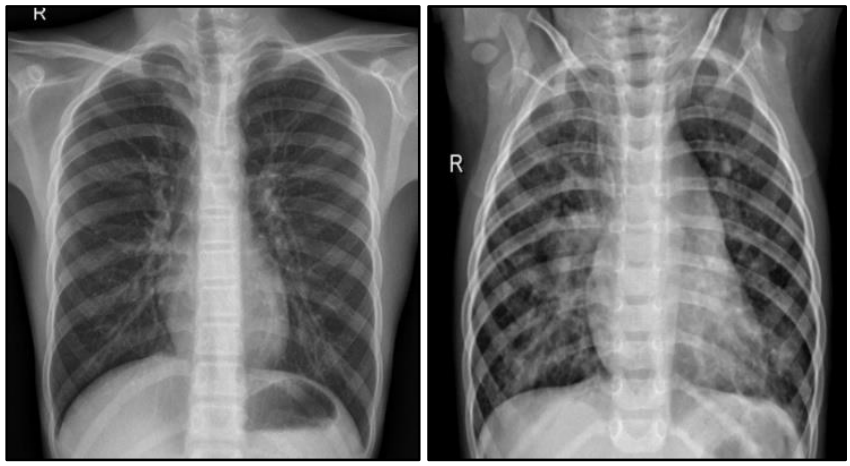

Gambar 3. Citra $x$-ray thorax Normal (kiri) dan Pneumonia (kanan)

Perbedaan utama paru-paru normal dan pneumonia adalah adanya infiltrat pada bagian paruparu citra $x$-ray thorax. Infiltrat sendiri adalah suatu bercak atau flek yang ada pada paru-paru yang muncul pada citra $x$-ray thorax. Munculnya infiltrat berarti pada paru-paru terdapat dahak (тисиs) yang mengakibatkan suatu peradangan pada paru-paru. Gambar 3 menunjukkan citra X-ray thorax Normal dan Pneumonia

Tabel 1. Data yang digunakan

\begin{tabular}{llll}
\hline No & Nama Data & Jenis Data & Jumlah Data \\
\hline 1 & Citra $X$-Ray Thorax Normal & Database & 50 \\
\hline 2 & Citra $X$-Ray Thorax Pneumonia & Database & 50 \\
\hline 3 & Citra X-Ray Thorax Normal & Data Uji & 10 \\
\hline 4 & Citra X-Ray Thorax Pneumonia & Data Uji & 10 \\
\hline
\end{tabular}

\subsection{Color Histogram}

Dimulai dengan input citra lalu membaca nilai RGB dari tiap pixel citra yang di-input-kan. Selanjutnya membagi nilai RGB menjadi 64 Red, 64 Green dan 64 Blue [10]. Nilai 64 berisi nilai warna untuk nilai 0-3 maka masuk dalam nilai RGB 1, 4-7 masuk dalam nilai RGB 2 dan 
seterusnya sampai 255. Sehingga total hasil nilai yang dikeluarkan adalah 64 x 3 (RGB) yaitu 192. Lalu membuat variabel kelas yang berisi nilai kluster dari angka 1-256, dan menghitung jarak nilai histogram ke nilai kluster. Bila nilai sama maka masuk dalam pengelompokan nilai kluster apabila tidak maka akan akan diulangi sampai nilai kluster di temukan.

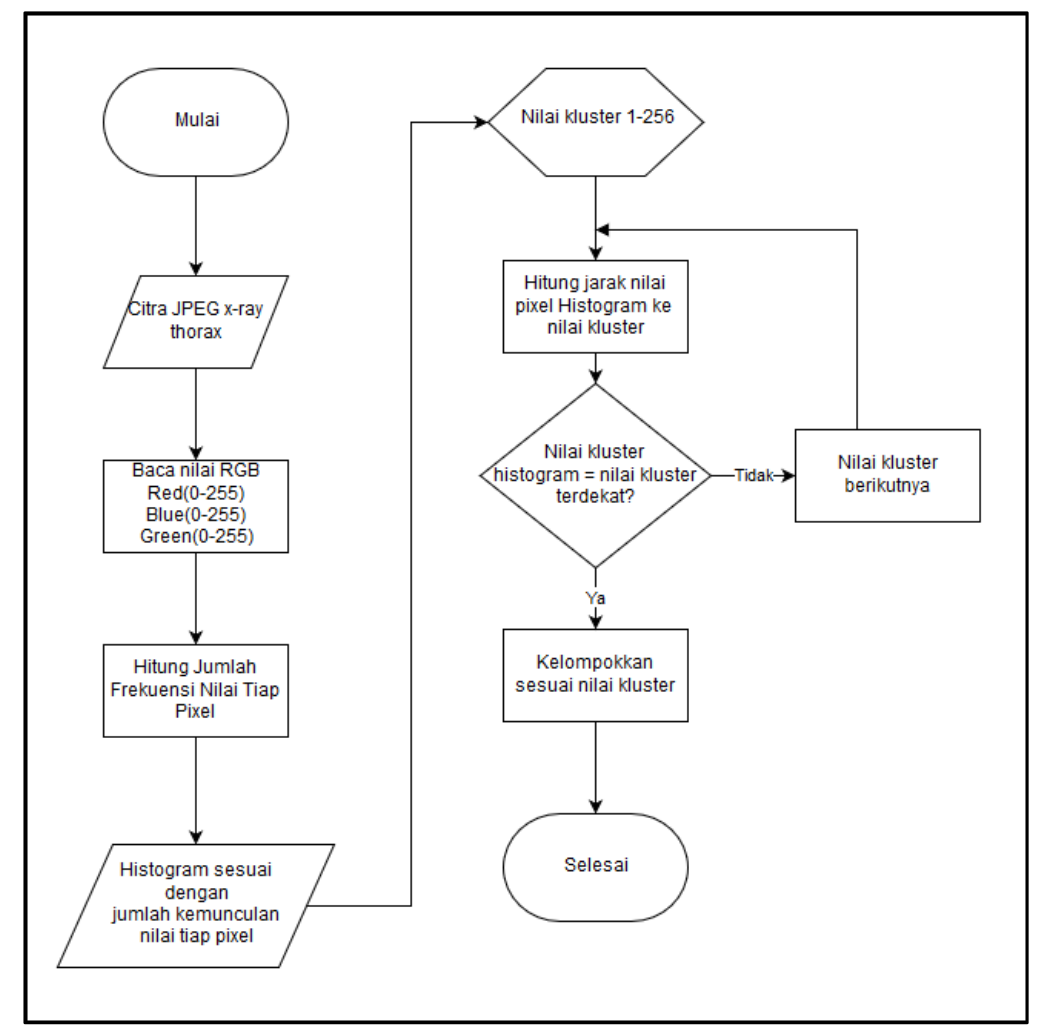

Gambar 5. Flowchart Color Histogram

\subsection{Discrete Cosine Transform}

Proses dimulai dengan membaca citra yang telah di-input-kan sebagai matriks. Pembacaan citra menjadi matriks dilakukan dengan pembacaan masing-masing pixel. Setiap pixel berisi nilai perpaduan 3 warna RGB, dimana jumlah nilai pixel nanti adalah penjumlahan dari masing-masing nilai RGB. Contoh apabila terdapat gambar yang memiliki pixel 16x16 maka gambar tersebut memiliki elemen matriks 16x16. Masing-masing pixel berisi perpaduan nilai warna RGB dengan total nilai warna 256. 


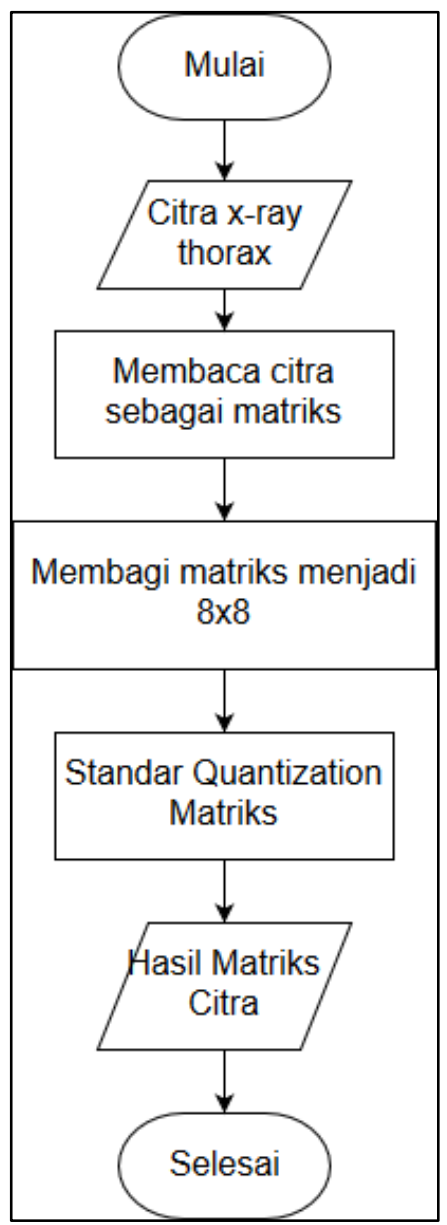

Gambar 6. Flowchart Discrete Cosine Transform

Dalam setiap blok dilakukan perhitungan untuk menjadikan dalam matriks 8x 8 dengan rumus sebagai berikut.

$$
\operatorname{DCT}(i, j)=\frac{2}{N} C(i) C(j)+\sum_{x=0}^{N-1} \sum_{x=0}^{N-1} \operatorname{pixel}(x, y) \cos \left[\frac{(2 x+1) i \pi}{2 N}\right] \cos \left[\frac{(2 y+1) j \pi}{2 N}\right]
$$

Keterangan:

$$
\begin{aligned}
& \operatorname{DCT}(i, j)=\text { nilai DCT indeks ke- }(i, j) \\
& N=\text { ukuran matriks } \\
& \text { pixel }(x, y)=\text { nilai pixel pada indeks ke- }(x, y) \\
& C(i), C(j)=1 \text { jika } i, j>0 \\
& C(i), C(j)=1 /(\text { akar } 2) \text { jika } i, j=0
\end{aligned}
$$

Pembagian matriks menjadi 8x8 digunakan karena hasil optimasi dari citra bertipe JPEG. Jika menggunakan matriks yang lebih besar maka gambar akan kurang mulus dan dapat mengurangi hasil kompresi, namun bila menggunakan matriks yang lebih kecil maka kuantisasi menjadi kurang fleksibel untuk dikompresi. 
Pembagian matriks $8 \times 8$ dapat dicontohkan dengan apabila mempunyai matriks 16x16 maka untuk mengubahnya menjadi $8 \times 8$ adalah dengan membaginya dengan 8 . Sehingga tiap bagian matriks akan berisi 2 nilai kolom matriks yang dijadikan 1 sehingga menjadi matriks 8x8. Setelah menjadi matriks $8 \times 8$ maka selanjutnya adalah menghitung nilai standar kuantisasinya dengan membagi matriks 8x8 dengan matriks kuantisasi umum. Pembagian dengan matriks kuantisasi umum mempunyai rumus sebagai berikut.

$$
\text { round }\left(\frac{\text { nilai matriks gambar input }}{\text { nilai matriks kuantisasi umum }}\right)
$$

\subsection{Gray Level Co-Occurrence Matrix}

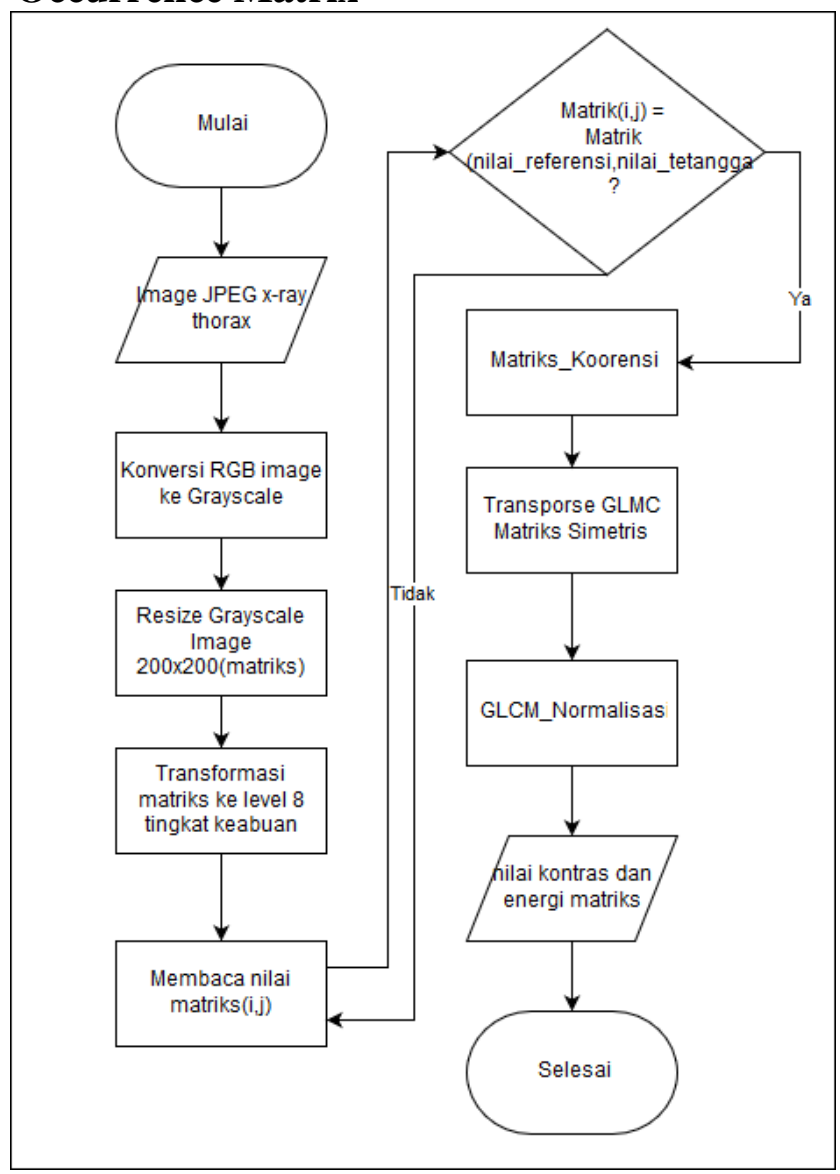

Gambar 7. Flowchart GLCM

Untuk flowchart GLCM dimulai dengan konversi citra ke grayscale dengan perhitungan $((0,2989 \times \mathrm{R})+(0,5870 \times \mathrm{G})+(0,1140 \times \mathrm{B}))$ karena setiap citra mempunyai nilai RGB tertentu. Sehingga nanti hasil perubahan menjadi grayscale hanya mempunyai 1 kanal warna. Lalu merubah citra menjadi matriks 200 x 200, yang kemudian dibagi menjadi 8 level tingkat keabuan. Tabel derajat keabuan terdapat pada Tabel 2. 
Tabel 2. Derajat keabuan

\begin{tabular}{ll} 
Skala & Nilai \\
\hline 0 & $0-31$ \\
\hline 1 & $32-63$ \\
\hline 2 & $64-95$ \\
\hline 3 & $96-127$ \\
\hline 4 & $128-159$ \\
\hline 5 & $160-191$ \\
\hline 6 & $192-223$ \\
\hline 7 & $224-255$ \\
\hline
\end{tabular}

Perhitungan kesamaan dengan menggunakan euclidean distances. Misalkan titik pertama mempunyai kordinat $(1,2)$. Titik kedua ada di kordinat $(5,5)$. Caranya adalah kurangkan setiap kordinat titik kedua dengan titik yang pertama. Yaitu, (5-1,5-2) sehingga menjadi (4,3). Kemudian pangkatkan masing-masing sehingga memperoleh $(16,9)$. Kemudian tambahkan semuanya sehingga memperoleh nilai $16+9=25$. Hasil ini kemudian diakarkan menjadi 5 . Sehingga jarak euclideannya adalah 5. Berikut rumus perhitungan euclidean distances [11] [12]

$$
d=\sqrt{\left(x_{2}-x_{1}\right)^{2}+\left(y_{2}-y_{1}\right)^{2}}
$$

Keterangan :

$d=$ tingkat kesamaan (similarity)

$x 1, y 1=$ nilai matriks pertama

$x 2, y 2=$ nilai matriks kedua

\section{Hasil dan Pembahasan}

Data X-ray thorax yang digunakan pada penelitian ini sebanyak 120 data yang diperoleh dari Rumah Sakit Khusus Paru (RSKP) Respira Bantul. Data terdiri dari 60 data paru-paru normal dan 60 data mengalami pneumonia. Data penelitian yang telah diperoleh selanjutnya akan dibagi menjadi data training dan data testing. 100 data digunakan sebagai data training dan 20 data digunakan sebagai data testing. Data training digunakan untuk melatih sistem agar saat melakukan deteksi dapat mendapatkan acuan yang tepat, sedangkan data testing digunakan untuk menguji sistem dapat berjalan dengan baik atau tidak.

Proses pertama yang dilakukan pada penelitian ini adalah proses color histogram, dilanjutkan dengan kompresi citra dengan metode Discrete Cosine Transform. Citra tersebut kemudian menjadi masukkan untuk proses ekstraksi fitur menggunakan GLCM. Proses GLCM menggunakan 3 fitur yaitu sudut, contrast dan energi. Proses selanjutnya perhitungan kesamaan (fiture matching) dengan citra yang ada pada database menggunakan nilai persamaan euclidean distance. Semakin kecil nilai Euclidean maka semakin mirip/cocok citra tersebut dengan citra yang ada di dalam database. 
Pengujian bertujuan untuk mengetahui tingkat akurasi deteksi citra x-ray thorax. Pengujian pertama menggunakan data uji yang diambil dari sebagian data latih (data training). Data uji yang digunakan 20 data uji dari keseluruhan data training sebanyak 100 data. Hasil pengujian yang pertama menunjukkan bahwa untuk seluruh data uji, seluruhnya dapat dikenali dengan benar, atau tingkat akurasi pengenalanya sebesar 100\%. Hal ini membuktikan bahwa sistem dapat mengenali citra $\mathrm{x}$-ray thorax yang sudah dimasukkan ke dalam data latih sebelumnya dengan sangat baik.

Pengujian kedua menggunakan 20 citra x-ray thorax dengan perincian 10 data normal dan 10 data pneumonia yang belum ada dalam latih. Hasil pengujian dapat dilihat pada tabel 3 . Berdasarkan tabel 3 menunjukkan tingkat akurasinya sebesar 95\%, dimana dari 20 data uji ada satu data yang salah dalam mendeteksi.

Tabel 3. Pengujian Validasi Data

\begin{tabular}{llllll}
\hline No & Nama Citra Uji & Hasil Pakar & Citra Kenal pada Sistem & Euclidean & Keterangan \\
\hline 1 & Normal_1.jpeg & Normal & Normal_39 & 0,1285 & Benar \\
\hline 2 & Normal_2.jpeg & Normal & Normal_33 & 0,1663 & Benar \\
\hline 3 & Normal_3.jpeg & Normal & Normal_33 & 0,1663 & Benar \\
\hline 4 & Normal_4.jpeg & Normal & Normal_9 & 0,3554 & Benar \\
\hline 5 & Normal_5.jpeg & Normal & Normal_16 & 0,1554 & Benar \\
\hline 6 & Normal_6.jpeg & Normal & Normal_28 & 0,1215 & Benar \\
\hline 7 & Normal_7.jpeg & Normal & Normal_6 & 0,2098 & Benar \\
\hline 8 & Normal_8.jpeg & Normal & Normal_33 & 0,1773 & Benar \\
\hline 9 & Normal_9.jpeg & Normal & Normal_46 & 0,1599 & Benar \\
\hline 10 & Normal_10.jpeg & Normal & Normal_29 & 0,893 & Benar \\
\hline 11 & Pneumonia_11.jpeg & Pneumonia & Pneumonia_47 & 0,793 & Benar \\
\hline 12 & Pneumonia_12.jpeg & Pneumonia & Pneumonia_10 & 0,2686 & Benar \\
\hline 13 & Pneumonia_13.jpeg & Pneumonia & Pneumonia_10 & 0,2686 & Benar \\
\hline 14 & Pneumonia_14.jpeg & Pneumonia & Pneumonia_9 & 0,920 & Benar \\
\hline 15 & Pneumonia_15.jpeg & Pneumonia & Pneumonia_9 & 0,841 & Benar \\
\hline 16 & Pneumonia_16.jpeg & Pneumonia & Pneumonia_28 & 0,1385 & Benar \\
\hline 17 & Pneumonia_17.jpeg & Pneumonia & Normal_49 & $\mathbf{0 , 1 8 0 4}$ & Salah \\
\hline 18 & Pneumonia_18.jpeg & Pneumonia & Pneumonia_18 & 0,1503 & Benar \\
\hline 19 & Pneumonia_19.jpeg & Pneumonia & Pneumonia_28 & 0,1758 & Benar \\
\hline 20 & Pneumonia_20.jpeg & Pneumonia & Pneumonia_36 & 0,2436 & Benar \\
\hline
\end{tabular}

\section{Kesimpulan}

Content Based Image Retrieval dapat mengidentifikasi citra $x$-ray thorax normal atau mengalami pneumonia dengan ekstraksi fitur Color Histogram, Discrete Cosine Transform dan Gray Level Cooccurence Matrix. Metode pencarian jarak terdekat Euclidean Distance dapat digunakan untuk menghitung jarak terdekat nilai vektor dari citra input dan database. Hasil pengujian menunjukkan bahwa fitur ekstraksi GLCM dengan pengukuran kemiripan Euclidean Distance diperoleh akurasi sebesar 95\% pada data latih 100 dan data uji 20, dengan jumlah citra yang ditampilkan 6. Sedangkan bila pengujian menggunakan data yang sudah dilatihkan menghasilkan akurasi $100 \%$. 


\section{Daftar Pustaka}

[1] D. Putra, Pengolahan Citra Digital, Yogyakarta: Andi, 2010.

[2] A. V. Faria, K. Oishi, S. Yoshida, A. Hillis, M. I. Miller and S. Mori, "Content-Based Image Retrieval fro Brain MRI: An Image-Searching Engine and Population-Based Analysis to Utilize past Clinical Data for Future Diagnosis," NeuroImage. Clinical, vol. 7, p. 367-376, 2015.

[3] R. Rahmadewi and R. Kurnia, "Klasifikasi Penyakit Paru Berdasarkan Citra Rontgen dengan Metoda Segmentasi Sobel," Jurnal Nasional Teknik Elektro, vol. 5, no. 1, pp. 7$12,2016$.

[4] D. A. Kusuma and C. Chairani, "Rancang Bangun Sistem Pakar Pendiagnosa Penyakit Paru-Paru Menggunakan Metode Case Based Reasoning," Jurnal Infotel, vol. 6, no. 2, pp. 57-62, 2014.

[5] J. Lin and H. Irsyad, "Klasifikasi Pneumonia Pada Citra X-Rays Paru-paru Menggunakan GLCM dan LVQ," Jurnal Algoritme, vol. 1, no. 2, pp. 184-194, 2021.

[6] M. R. Tasya, B. Soedjiono and E. T. Luthfi, "Klasifikasi Kualitas Kematangan Worter Menggunakan Metode GLCM dan Neural Network," Junal Fateksa, vol. 5, no. 2, pp. 1$10,2020$.

[7] D. P. Pamungkas, "Ekstraksi Citra Menggunakan Metode GLCM dan KNN untuk Identifikasi Jenis Anggrek," Jurnal INNOVATICS, vol. 1, no. 2, pp. 51-56, 2019.

[8] R. Widodo, A. W. Widodo and A. Supriyanto, "Pemanfaatan Ciri Gray Level CoOccurance Matrix (GLCM) Citra Buah Jeruk Keprok (Citrus Reticulata Blanco) untuk Klasifikasi Mutu," Jurnal Pengembangan Teknologi Informasi dan Ilmu Komputer, vol. 2, no. 11, pp. 5769-5776, 2018.

[9] H. Jogiyanto, Analisis dan Desain Sistem Informasi : pendekatan terstruktur teori, Yogyakarta: Andi Offset, 2005.

[10] P. Mudjirahardjo, H. Suyono and R. A. Setyawan, "Real time object localization based on histogram of s-RGB," in AIP Conference Proceedings, Volume 1883, Issue 1, id.020037, 2017.

[11] R. Wulanningrum and A. Rachmad, "Pengenalan Rumput Laut Menggunakan Euclidean Distance Berbasis Ekstraksi Fitur," in Seminar Nasional Aplikasi Teknologi Informasi 2012 (SNATI 2012), Yogyakarta, 2012.

[12] M. M. B, Andriana and A. S. Hidayat, "Implementasi Algoritma GLCM dan MED pada Aplikasi Pendeteksi Kolesterol Melalui Iris Mata," MINDJournal, vol. 2, no. 2, pp. 23-41, 2017. 